\title{
FANTASMAGORIA: A CHAVE PARA COMPREENSÃO DA MODERNIDADE EM WALTER BENJAMIN
}

Francisco Rogelio dos Santos

\begin{abstract}
RESUMO
Esse artigo intenta analisar a relação intrínseca que Benjamin estabelece entre fantasmagoria como um processo social de constituição da modernidade e sua percepção das mudanças ocorridas na Paris do século XIX. Será feito uma exposição da figura do flâneur e do colecionador, como elementos primordiais para compreendermos a relação dos habitantes com os novos espaços da cidade, assim como na vida privada e o impacto que estes fatos irão desencadear no subconsciente dos homens
\end{abstract}

Palavras-chave: Fantasmagoria. Flâneur. Colecionador. Paris.

\section{PHANTASMAGORIA: THE KEY TO UNDERSTANDING MODERNITY ACTION IN WALTER BENJAMIN}

\begin{abstract}
This article attempts to analyze the intrinsic relationship that Benjamin established between phantasmagoria as a social process of constitution of modernity and their perception of changes in nineteenth-century Paris. It will be an exhibition of the flaneur figure and collector, as key elements to understand the relationship of people to the new spaces in the city, as well as in private life and the impact that these events will trigger the subconscious of men.
\end{abstract}

Keywords: Phantasmagoria. Flâneur. Collector. Paris. 
No texto de 1939, "Paris, A Capital do Século XIX", do livro "Passagens", Walter Benjamin cita por sete vezes apenas na introdução, o termo fantasmagoria. Isso evidência a importância do conceito para entendermos 0 que 0 filosofo compreende sobre a modernidade, em especial as características da capital francesa e seus habitantes no século XIX na análise benjaminiana. Pretendemos também, demonstrar como a análise de Benjamin é adequada para caracterizarmos o mundo contemporâneo que em si, é marcado por relações mercadológicas, frias e narcotizadas. Para tanto, partiremos da compreensão que a fantasmagoria seria para Benjamin uma imagem criada pelo homem, que adquire uma realidade própria, passando a ser ilusória e independente daquele que a criou. Com isso, na prática, o homem passa a não mais conhecê-la, e o pior, tê-la não como criação sua, mas como autônoma e, imagem verdadeira do mundo. O conceito de fantasmagoria ocupa no pensamento de Walter Benjamin, uma posição central para a compreensão da modernidade. Nesse sentido, entender a concepção antropológica do autor, no que diz respeito ao homem moderno, necessariamente é compreender a intrínseca relação entre alguns fatores, a saber: economia e técnica, relações sociais no contexto do espaço metropolitano da grande cidade a partir da imagem criada pelo sujeito dele mesmo (passando ela a ser tida como real), e a imagem real que passa a não ser percebida.

No decorrer deste trabalho, é exposta a tentativa de compreender o conceito de fantasmagoria na obra de Benjamin, "as passagens", mas específico nos textos "Paris, capital do século XIX" (1935), e "Paris, a capital do século XIX" (1939). Buscamos demonstrar como o autor, ao se apropriar em sua análise da Paris do século XIX, explora as mudanças estruturais e arquitetônicas da capital francesa, entre 1822 a 1837, para desvelar a fantasmagoria da civilização moderna em todos os aspectos da vida do homem. Ao expor a relação entre os fatores apresentados acima, tentaremos compreender, partindo da idéia cristalizada que se tinha de história, como isso contribuiu para a construção de uma imagem irreal que o homem faz de si mesmo e das relações sociais que mantém no contexto de uma sociedade 
capitalista e suas estratégias de anular o sujeito frente à produção humana em todas as instâncias, seja na arte, no comercio ou nas relações sociais.

É de nosso interesse, fazer uma abordagem sistemática do texto "Paris, A Capital do Século XIX", demonstrando como Benjamin irá desvelar nos mais diversos aspectos, a fantasmagoria da capital francesa, e em seus habitantes. Em especial, trataremos de duas personagens chave nesse contexto, trata-se da figura do flânuer e do colecionador. Na penúltima parte deste texto será, portanto, exposto uma análise da importância dos supracitados personagens, para configurar o contexto social e o momento histórico em que o capitalismo encontrava-se e como essa relação possibilita o surgimento das imagens fantasmagóricas tratadas pelo pensador alemão.

Explicitar como a análise benjaminiana é adequada para compreendermos o mundo contemporâneo é, nosso esforço na última parte deste trabalho. Levando em conta, que nosso tempo é marcado pelo consumo e pela indústria entretenimento - lembrando que no momento histórico que Benjamin viveu, essa relação não era tão intensa quanto hoje -, que em um nível muito elevado e que cada vez mais, as relações humanas são visíveis pela frieza, e narcotizadas pela imagem irreal, fantasmagórica, que nossa sociedade cria de si mesma.

\section{A fantasmagoria como traço do homem moderno}

Benjamin nos apresenta a fantasmagoria como um traço presente em todos os aspectos do homem moderno, conforme ele, isso ocorre em conseqüência de uma sensação de vertigem ocasionada pela compreensão da história humana no decorrer do século $\mathrm{XIX}^{1}$, como algo congelado, cristalizado, como uma representação coisificada da civilização. Esse entendimento da história, pouca dava importância ao esforça da sociedade "real", como transmissora e possibilitadora da riqueza das formas de vida e criações da humanidade. Ao analisarmos os textos "Paris, capital do século XIX" (1935), e

\footnotetext{
1 O conceito da filosofia da história de Walter Benjamin, que é usado aqui, é da história dos vencedores, ligada a uma narrativa progressista. Este é alvo de criticas veementes do pensador.
}

Graduado em Filosofia - Licenciatura, pela Universidade Estadual Vale do Acaraú - UEVA, atualmente, Mestrando em Filosofia pela Universidade Estadual do Ceará - UECE. Brasileiro, residente em Sobral - CE. E-mail: rogellyo@hotmail.com 
"Paris, a capital do século XIX" (1939), percebemos claramente a intenção do pensador, em esclarecer as conseqüências dessa concepção.

É fundamental para Benjamin, compreendermos os fatores que levaram a fantasmagoria na modernidade, para isso nos escreve propondo:

Nossa pesquisa procura mostrar como, em consequência dessa representação coisificada da civilização, as formas de vida nova e as novas criações de base econômica e técnica, que devemos ao século XIX, entram no universo de uma fantasmagoria. (BENJAMIN, 2009, 53)

A análise benjaminiana sobre a modernidade, parte justamente da relação dos homens no contexto (na forma de vida que é criada pela economia capitalista) entre economia e a técnica, com as criações proporcionadas por elas no âmbito ideológico, "na imediatez da presença sensível" (BENJAMIN, $2009,53)$, e como a partir disso, desembocam em uma fantasmagoria. Dessa maneira, as mudanças nas relações humanas, as transformações estruturais e arquitetônicas, seja nas ruas da capital francesa, seja no ambiente privado de um escritório, na lógica do comércio de mercadorias, ou na experiência singular de um sujeito, são utilizadas por ele, para demonstrar a fantasmagoria da civilização moderna.

A fantasmagoria configura-se como uma realidade sempre presente. A construção humana da sua própria imagem, ganha uma autonomia em relação ao sujeito, passando ele a viver narcotizado no seio de sua própria criação que é tida como real e ao mesmo tempo estranha ao seu criador (o homem). Benjamin associa a noção de imagem com a de fantasmagoria, vejamos:

A qualidade pertencente à mercadoria como seu caráter de fetiche precede igualmente à sociedade produtora de mercadorias - não como é nela mesma, sem dúvida, mas como quando se representa a si mesma e julga entender a si mesma sempre que se abstrai do fato de que produz, precisamente, mercadorias. A imagem que ela produz de si mesma dessa maneira, e que ela habitualmente rotula de sua cultura, corresponde ao conceito de fantasmagoria. (BENJAMIN, 2009, 669).

O olhar de Benjamin nesse sentido consegue captar as expressões onde a fantasmagoria esta presente na modernidade, a partir dessa percepção de imagem criada. Em "Paris, a capital do século XIX", ele capta os elementos

Graduado em Filosofia - Licenciatura, pela Universidade Estadual Vale do Acaraú - UEVA, atualmente, Mestrando em Filosofia pela Universidade Estadual do Ceará - UECE. Brasileiro, residente em Sobral - CE. E-mail: rogellyo@hotmail.com 
subjetivos da realidade, expressos nas várias formas de representação do mundo social da cidade, demonstrando como a fantasmagoria está envolta no homem moderno. Desse modo, sua pesquisa tem início na análise das mudanças estruturais e arquitetônicas ocorridas da capital francesa a partir de 1822, até meados de 1837:

Assim apresentam-se as "passagens", primeiras formas de aplicação do ferro; assim apresentam-se as exposições universais, cujo acoplamento à industria de entretenimento é significativo; na mesma ordem de fenômenos, a experiência de flâneur, que se abandona às fantasmagorias do mercado. (BENJAMIN, 2009, 54).

Essas são as palavras de Benjamin ao falar sobre Paris, com um olhar criterioso, ele consegue vê as mudanças na cidade e em seus habitantes. O filósofo observa o particular, dito acima na figura do flâneur ${ }^{2}$, como portador de manifestações universais. Manifestações estas, em aspectos culturais e específicos da realidade, que desvelam a fantasmagoria geral da Paris do século XIX.

Benjamin adianta a identificação dos aspectos fantasmagóricos que encontrará, quer seja nas ruas de Paris, pela figura do flâneur, quer seja no universo particular do interior da casa burguesa ou, ainda, no processo de urbanização da cidade de Paris realizado por Haussmann ao nos falar.

Na mesma ordem de fenômenos, a experiência do flâneur, que se abandona às fantasmagorias do mercado. A essas fantasmagorias do mercado, nas quais os homens aparecem somente sob seus aspectos típicos, correspondem as do interior, que se devem à inclinação imperiosa do homem a deixar nos cômodos em que habita a marca de sua existência individual privada. Quanto à fantasmagoria da própria civilização, encontrou seu campeão em Haussmann, e sua expressão manifesta nas transformações que ele realizou em Paris. (BENJAMIN, 2009, 54)

As mudanças ocorridas na capital francesa, denotam a retirada da espontaneidade da criação. O homem agora passa a viver em um espaço determinado, mesmo nas relações que mantém com outros homens não há mais lugar para a criatividade. ${ }^{3}$

\footnotetext{
${ }^{2}$ Personagem do poeta Baudelaire, no livro "Flores do Mal" de 1857.

${ }^{3}$ Torna-se importante esclarecer que o conceito de fantasmagoria desenvolvido por Benjamin, não trata-se apenas de um alargamento metodológico do fetiche de Marx. Benjamin vai além, para ele a imagem criada pelo homem da sua própria realidade, é algo bem antigo, que remete ao orgulho humano, um espécie de narcisismo. A fantasmagoria na obra de Benjamin ilumina

Graduado em Filosofia - Licenciatura, pela Universidade Estadual Vale do Acaraú - UEVA, atualmente, Mestrando em Filosofia pela Universidade Estadual do Ceará - UECE. Brasileiro, residente em Sobral - CE. E-mail: rogellyo@hotmail.com
} 


\subsection{A percepção benjaminiana sobre os espaços e as relações onde a fantasmagoria aparece na capital francesa}

No texto de 1939, Benjamin discorre em cinco secções como a fantasmagoria esta presente na vida humana. Ele retira a natureza da experiência moderna inicialmente em Fourier ou as passagens, elencando dois motivos para o surgimento das passagens na cidade de Paris. O pensador faz menção, ao comercio têxtil como o primeiro a possibilitar a construção de maneira coletiva dos armazéns de mercadoria de luxo e, a utilização da arte para expor os produtos. O segundo motivo, foi o início das construções metálicas. Essas construções adquirem para Benjamin, um poder no subconsciente dos sujeitos. O material de construção utilizada para fazê-las, é uma inovação, o ferro. Aos poucos ele ganha status e vai transformando as paisagens de Paris. As mudanças que ocorrem na capital francesa modificam também os hábitos de seus habitantes.

Benjamin cita Fourier como o propulsor da criação das passagens. Elas inicialmente serviam para fins comerciais, com Fourier, tornam-se espaço de residências. E é, "nessas cidades passagens" (BENJAMIN, 2009, 56), composto por residências, que as construções ganham aparência de fantasmagoria. Cada vez mais, a imagem ilusória de uma realidade vai criando independência em relação ao sujeito. Essa imagem irreal da realidade, ganha muita força no espaço da civilização do aglomerado urbano. Surge também aí, a figura do flâneur ${ }^{4}$, como aquele que se apodera do cenário de ilusão fantasmagórico e ao contemplá-lo passa a tê-lo como real.

$\mathrm{Na}$ seção Grandville ou as exposições universais, a análise benjaminiana sobre a fantasmagoria novamente aparece em duas passagens, na primeira, quando o filosofo fala das exposições universais, afirmando que

aqueles aspectos ambíguos da experiência coletiva e solitária da existência, expressos como fenômeno cultural e condicionados por uma forma particular de avanço tecnológico.

${ }^{4}$ Trataremos no ponto 2.1 da importância do flânuer para Benjamin, fazermos uma abordagem comparativa entre o colecionar e a personagem de Baudelaire citada por Benjamin.

Graduado em Filosofia - Licenciatura, pela Universidade Estadual Vale do Acaraú - UEVA, atualmente, Mestrando em Filosofia pela Universidade Estadual do Ceará - UECE. Brasileiro, residente em Sobral - CE. E-mail: rogellyo@hotmail.com 
elas dão acesso a uma fantasmagoria onde as pessoas vão para se deixar distrair. No segundo momento, a utilização do ferro fundido da para a construção de um balcão, que representaria para a exposição, o anel de saturno. Aqueles que ali entram - no espaço da exposição -, entrariam também numa fantasmagoria. Conforme Benjamin as [...] exposições universais são os centros de peregrinação ao fetiche mercadoria e nasceram do desejo de 'divertir as classes laboriosas e torna-se para estas uma festa, de emancipação para elas" (BENJAMIN, 2009, 57).

Em um trecho anterior do mesmo texto, cita:

As exposições universais idealizam o valor de troca das mercadorias. Criam um quadro no qual seu valor de uso passa a segundo plano. As exposições universais constituíram uma escola onde as multidões, forçosamente afastadas do consumo, se imbuíram do valor de troca das mercadorias a ponto de se identificarem com ele: "É proibido tocas nos objetos expostos". (BENJAMIN, 2009, 57).

Benjamin percebe a sutil intenção por trás das exposições, que era justamente a formação e educação das classes populares, visando um certo amor pelo trabalho. Ao mesmo tempo, o espaço das exposições transportavam os visitantes em habitantes de saturno, conduzindo-os a uma visão fantasmagórica da realidade. Tudo era preparado de tal modo a conduzir aqueles que estavam no local, a uma realidade entorpecida, uma imagem criada e a partir dali, tida com real. [...] as exposições universais constroem um mundo feito de "especialidades". As fantasias de Grandville realizam a mesma coisa. [...] (BENJAMIN, 2009, 58). Para Benjamin, as exposições universais idealizam o valor de troca das mercadorias deixando dessa forma, seu valor de uso em segundo plano. A fantasmagoria remete ao lado mais exuberante, visível, a um certo espetáculo da mercadoria, e dessa maneira ocasiona um impacto subjetivo nos que iam as exposições, pois nelas criam-se uma imagem paralela - fantasmagórica -, que aos poucos toma o lugar da realidade, assumindo por fim o papel principal de imagem real do mundo.

Em Luís Bonaparte ou o intérieur, a fantasmagoria será associada à idéia da solidão, do individualismo, da individualidade do homem privado. 0 escritório passa a ser seu complemento. Benjamin lança o olhar para o interior

Graduado em Filosofia - Licenciatura, pela Universidade Estadual Vale do Acaraú - UEVA, atualmente, Mestrando em Filosofia pela Universidade Estadual do Ceará - UECE. Brasileiro, residente em Sobral - CE. E-mail: rogellyo@hotmail.com 
da casa burguesa onde o escritório é seu complemento e, ainda, onde o homem burguês refugia-se da realidade, criando uma realidade de fantasmagoria num universo fechado, privado. "[...] numa tendência de indenizar-se da ausência de rastros da vida privada na grande cidade [...]" (BENJAMIN, 2009, 59-60). Através desse aspecto, pode-se, identificar a constituição fantasmagórica presente no mundo público e privado na modernidade. O espaço privado passou a ser visto sobre perspectivas diferentes tanto para os burgueses, como para os pobres da sociedade francesa, como nos afirma D' Angelo ao falar sobre os pobres da cidade de Paris:

[...] Constrangidos a viverem amontoados, os pobres eram levados a um uso privativo do espaço público e a manifestações visando à redefinição de ambos. A forma mais sugestiva desse entrelaçamento entre espaço privado e o público é, sem dúvida, a barricada (D’ANGELO, 2006, 240-241)

Para o pobre de Paris, a barricada, que seria uma forma de resistência das classes menos favorecidas, ${ }^{5}$ representava a união entre 0 público e o privado, já que na prática como dito acima, eles eram em razão das circunstâncias, eram obrigados a fazerem do espaço público, o local de sua privacidade. Já para o burguês, a casa é por excelência, domínio privado. Para Walter Benjamin, é na moradia burguesa, que surge a figura do colecionador ${ }^{6}$. Ele será uma espécie de refúgio para a arte, tendo o papel de retirar dela a perspectiva de mercadoria, Benjamin escreve na seção Luís Filipe:

O interior é o asilo onde se refugia a arte. O colecionador se torna o verdadeiro ocupante do interior. Seu ofício é a idealização dos objetos. A ele cabe esta tarefa de Sísifo de retirar das coisas, já que as possui, seu caráter de mercadoria. [...] (BENJAMIN, 2009, 59).

Contrapõem-se de certo modo ao colecionador, a figura do flânuer, por suas características de observador das ruas - portanto do espaço público -, da multidão, das lojas de departamento da capital francesa.

Em Baudelaire ou as ruas de Paris, Benjamin escreve:

\footnotetext{
${ }^{5}$ A temática que será tratada ao longo de nossa exposição.

${ }^{6}$ Desenvolveremos com maior atenção a figura do colecionador em Benjamin, no ponto 2.2 deste trabalho.
}

Graduado em Filosofia - Licenciatura, pela Universidade Estadual Vale do Acaraú - UEVA, atualmente, Mestrando em Filosofia pela Universidade Estadual do Ceará - UECE. Brasileiro, residente em Sobral - CE. E-mail: rogellyo@hotmail.com 
[...] A multidão é o véu através do qual a cidade familiar se transforma, para o flâneur, em fantasmagoria; Essa fantasmagoria, em que a cidade aparece ora como paisagem, ora como aposento, parece ter inspirado a decoração das lojas de departamentos que põem, assim, a própria flânerie a serviço de seus negócios; É aí que se manifesta, no coração do flânerie, uma fantasmagoria angustiante. Mas o novo que ele espreitou durante toda a sua vida não é feito de outra matéria que não dessa fantasmagoria do 'sempre igual'. (BENJAMIN, 2009, 61-62)

O termo fantasmagoria aparece, portanto, ligada as paisagens parisienses em um momento, em outro ao aposento, mas sempre associado à visão do flânuer - personagem de Baudelaire, utilizado por Benjamin em vários momentos de sua obra filosófica -, é a parir dele que Benjamin consegue captar "[...] o sentimento de uma profunda alienação" (BENJAMIN, 2009, 61), na paris do século XIX, a fantasmagoria do sempre igual. A análise do autor é sutil, mais extremamente perspicaz ao perceber, certa melancolia na sociedade francesa, pois aos olhos do filosofo, ela transforma tudo em mercadoria, tornando-se, ela própria em fantasmagoria, assim como seus habitantes, na imagem da multidão que circula nas galerias parisienses para unicamente fins mercadológicos. A multidão nesse sentido acaba por encobrir as particularidade dos indivíduos, entrar portando no meio dela representa para o sujeito, certa diluição da personalidade.

Benjamin afirma algo bastante interessante sobre o personagem de Baudelaire, ao escrever que "[...] na figura do flâneur, a intelectualidade familiariza-se com o mercado. Para lá, encaminha-se o flâneur, pensando dar apenas uma volta; mas, na verdade, é para encontrar um comprador [...]" (BENJAMIN, 2009, p. 61). A mobilidade do flâneur no interior da cidade dá a ele um sentimento de poder e a ilusão de estar isento de condicionamentos históricos e sociais. Esse talvez seja o motivo de sua partida para o mercado, ele imagina que é só para dar uma olhada para lojas e o movimento da multidão, mais acaba submetido às fantasmagorias que encontra no espaço público de grande circulação de mercadoria e de pessoas. O flâneur acaba sendo iludido e se entrega a uma espécie de mágica onde tudo é transformado, até mesmo o ser humana passa a ter o status de mercadoria. 
A última seção do texto "Paris, a capital do século XIX", Benjamin escreve como o título Haussmann ou as barricadas. Nela, o filosofo apropria-se da figura de Haussmann, ${ }^{7}$ para explicar como as mudanças arquitetônicas e o discurso de ódio contra as populações menos "instáveis da grande cidade", demonstram o caráter desumano da grande cidade, ao mesmo tempo, desvelando sua face fantasmagórica. As transformações na cidade, levado a cabo por Haussmann, deram aos moradores da cidade de Paris, a sensação de não estarem em suas casas. Obrigados a se afastarem do centro da cidade, o proletariado passa a viver nos arredores do grande centro urbano Benjamim escreve, "Na haussmannização de Paris a fantasmagoria se fez pedra"; projeto de urbanização empreendido pelo Barão de Haussmann tinha como propósito "[...] tornar para sempre impossível a construção de barricadas nas ruas de Paris" (BENJAMIN, 2009, 64). O ideal urbanístico de Haussmann eram as perspectivas sobre as quais se abrem longas fileiras de ruas. $O$ embelezamento estratégico da cidade, tinha como objetivo, caso houvesse uma revolta, o controle e dominação rápido e eficaz por parte da poder dos dominantes, no caso a burguesia. As barricadas nesse sentido, eram tidas como ilegais e extremamente proibidas.

Na conclusão do Exposé, nos é apresentado à última das fantasmagorias do século analisada por Benjamin, trata-se da fantasmagoria que segundo ele, completa a constelação de fantasmagorias" (BENJAMIN, $2009,66)$. A crítica de filosofo é direcionada à visão do universo que Blanqui ${ }^{8}$ desenvolve em sua obra "Eternité par lês Astre". Nas palavras do filosofo: "[...] Blanqui se preocupa em traçar uma imagem do progresso que - antiguidade

\footnotetext{
7 Georges-Eugène Haussmann GCNSC (Paris, 27 de Março de 1809 - Paris, 11 de Janeiro de 1891), largamente conhecido apenas como Barão Haussmann- o "artista demolidor", foi prefeito do antigo departamento do Sena (que incluía os atuais departamentos de Paris, Hauts-de-Seine, Seine-Saint-Denis e Val-de-Marne), entre 1853 e $1870 . \quad$ Durante aquele período foi responsável pelareforma urbana de Paris, determinada por Napoleão III, e tornou-se muito conhecido na história do urbanismo e das cidades. (Wikipédia)

${ }^{8}$ Louis-Auguste Blanqui, (Puget-Théniers, 1 de fevereiro de 1805 - Paris, 1 de janeiro de 1881) foi um teórico e revolucionário republicano socialista francês, associado erroneamente aos socialistas utópicos.
} 
imemorial, exibindo-se numa roupagem de última novidade - revela-se como fantasmagoria da própria história [...]" (BENJAMIN, 2009, 66).

Benjamin denuncia a visão positivista de um progresso contínuo e linear da sociedade. Conforme o filosofo essa idealização possui um caráter fantasmagórico, que na obra de Blanqui ganhou uma expressiva expressão.

\section{A figura do flâneur versus a figura do colecionador}

\subsection{0 flâneur}

O flâneur, descrito por Benjamin, é aquele que costumava sair as ruas da cidade de Paris, para observar as galerias, as lojas da capital francesa, ou seja, a experiência analisada pelo pensador no personagem de Baudelaire, é sua percepção visual, uma espécie de observação contemplativa. Mais a leitura de Benjamin não se resume a isso, pelo contrário, ele vê em flâneur o reflexo das mudanças sociais, arquitetônicas estruturais pela qual passava a capital da França.

O pensador irá enfatizar a maneira como o flâneur surge dentro das galerias, interiores, das salas de exibição, ou seja, nos espaços sociais criados. Como escreve Paula Tárcia "[...] o flâneur, além de ser observador, tem por característica ser aquele habitante que vive, sente e estabelece relações mais diretas e incisivas com a cidade [...]" (SILVA, 2013, 72).

Como nos afirma Ségio Roberto Massagli:

[...] a expansão sem precedência da economia industrial e a conseqüente explosão demográfica das cidades, em especial Londres e Paris, acarretaram no surgimento do ambiente urbano moderno, possibilitando novas formas de experimentar e perceber. Isso, por sua vez, requeria um novo modo de olhar para o mundo [...] (MASSAGLI, 2013, 56).

É nesse sinto que o flâneur, aparece no espaço público, como uma nova figura social. A existência do flâneur nas ruas poderia estar relacionada, com o crescimento das galerias, a sua decadência foi acelerada pela 
hausmanização das ruas de Paris. Com o nascimento da indústria de entretenimento associada ao aumento do consumo em uma nova fase do capitalismo, a multidão que inicialmente era o refugio do flâneur, passa a serem consumidores na busca de mercadorias.

Para Benjamin, a cidade de Paris, é transformada em fantasmagoria, aparecendo sobre duas perspectivas diferentes. Uma como paisagem, em outro momento como aposento. Essas transformações inspiram as lojas de departamento - elas parecem inspirarem-se no flânerie ${ }^{9}$ a serviço de seus próprios interesses -, é justo nelas que o flâneur encontra sua última parada. A esse respeito, Benjamin dirige sua atenção à relação entre o espetáculo da mercadoria e o olhar do flâneur. As mercadorias hipnotizantes que prendem seu olhar nas vitrines, e às quais ele extaticamente se rende, compelem o flâneur a vagar pelas ruas. É nesse sentido que Benjamin fala sobre a fantasmagoria do espaço a que o personagem de Baudelaire se dedicou.

As galerias, fornecem ao flâneur uma mundo em miniatura, um paronama das mercadorias, uma imagem do espetáculo do mundo do consumo capitalista. Assim, Benjamin caracteriza a Paris de Baudelaire como uma gastronomia dos olhos, seu personagem, o flâneur como uma espécie de caleidoscópio dotado de consciência.

\subsection{0 colecionador}

Ao contrário do flâneur que apenas contemplava as coisas, o colecionador tem como principal características justamente o toque, o que evidencia que ele é um espécie de modelo que faz um contraponto a imagem daquele. O colecionador é o exemplo de uma nova forma de sujeito fruto da

\footnotetext{
${ }^{9}$ Flânerie deriva da palavra flâneur, aquele que flana, caminha, passeia. O sentido de flanar conduz a uma travessia pela cidade, não somente a física; mas também, a criada pela urbe que habita em nós, na medida em que somos constituídos por relações imaginárias. Ou seja, flanar baseia-se num percurso épico que o flâneur empreende por muito conhecer a cidade. Embora o seu olhar sempre seja o do distanciamento, ele é antes de tudo um observador que sente a cidade," ele busca asilo na multidão" como bem disse Walter Benjamin. Dito isto a flânerie é o meio pelo qual se pode contemplar a cidade sem ser dela integrado, pois esse circular investigativo na cidade envolve reflexão e compreensão dos fenômenos que a envolvem. (O QUE É A FIANERIE?. Flanerie e linguagem. Disponível em: < http://flanerielinguagem.blogspot.com.br/2012/02/blog-post.html> Acesso em: 23 out 2015.)
}

Graduado em Filosofia - Licenciatura, pela Universidade Estadual Vale do Acaraú - UEVA, atualmente, Mestrando em Filosofia pela Universidade Estadual do Ceará - UECE. Brasileiro, residente em Sobral - CE. E-mail: rogellyo@hotmail.com 
modernidade, ele entra em cena como aquele que controla o mundo objetivo e o transfigura. Seu papel como afirma Benjamin é despir "[...] as coisas de seu caráter de mercadoria ao tomar posse delas [...]" (BENJAMIN, 2009, 59). O colecionador retira os objetos dos seus lugares e os coloca na prateleira.

Sua marca é o interior da casa burguesa, ele vive no espaço privado pois é lá que a arte se refugia. O colecionador torna-se assim, o verdadeiro ocupante do inteiro, só que o intérieur. Conforme Renata:

[...] O colecionador em Benjamin, enfim, é o sujeito que recolhe pela vida objetos-registros de uma história; objetos não úteis aos fins comuns, mas únicos e especialmente valiosos, cada um, dentro da coleção à qual pertencem. O colecionador benjaminiano possui os objetos quase que como peças de quebra-cabeças, que se relacionam entre si e que juntas 'montam' algo [...]. (FLORES, 2015)

Escreve Benjamin:

[...] O colecionador se compraz em suscitar um mundo não apenas longínquo e extinto, mas, ao mesmo tempo melhor, um mundo em que o homem, na realidade, é tão pouco provido daquilo de que necessita como no mundo real, mas em que as coisas estão libertadas da servidão de serem úteis. (BENJAMIN, 2009, 59)

O colecionador tem como objetivo não apenas fazer uma interpretação, mas também substituir o domínio do valor de exibição, por valor de uso. Na figura exemplar do colecionador batalhando contra a fantasmagoria. É nesse sentido que podemos falar que Benjamin identifica nele uma forma de subjetividade dotada de percepção tátil e memória prática.

\subsection{A fantasmagoria na contemporaneidade}

"[...] A fantasmagoria da cultura capitalista alcança seu desdobramento mais brilhante na exposição universal de 1867 [...]" (BENJAMIN, 2009, 45). No texto de 1934, "Paris, capital do século XIX", Benjamin, com sua fantástica capacidade de percepção, de leitura dos pequenos detalhes, que para a maioria passam desapercebidos, consegue fazer previsões quase premonitórias e captura a fantasmagoria das relações 
humanas. De certa forma, antecipa esse fenômeno que se intensificaram gigantescamente no contexto do mundo contemporâneo.

Em nosso tempo, a fantasmagoria manifesta-se de maneira mais brutal, tendo a seu favor, a indústria do entretenimento, acoplada a todo um sistema de coerção psicologia que o capitalismo avançado utiliza como instrumento de narcotização histórico - social. Nesse sentido, percebe-se a atualidade do pensamento de Benjamin como elemento chave para a compreensão da sociedade contemporânea, que tem no capitalismo globalizado sua maior expressão. Como escreve Luiz Carlos Andrade:

[...] hoje, tem-se uma proliferação de shopping centers, muito pouco apreciados pela França em geral, mas o comércio continua nas galerias e nas ruas como em qualquer capital cultural e desenvolvida da Europa; são os novos templos do consumo e do lazer, onde as mercadorias exercem todo o seu poder sobre os indivíduos que ali se encontram. Portanto, do interior da moradia burguesa do passado, com sua mobília e objetos de veneração organizando o mundo privado das famílias, a contemporaneidade, por um lado, apresenta a convivência privada organizada em condomínios, reproduzindo, na família, nesses novos ambientes fechados, o universo de relações sociais que as ruas da cidade já não proporcionam; por outro lado, os projetos urbanos (habitacionais, comerciais, públicos e, ainda, de revitalização de centros urbanos antigos) incorporam uma arquitetura que transforma espaços públicos em locais de pura exibição e contemplação, com acesso limitado às classes populares e trabalhadoras. (AQUINO, 2015)

A leitura que Benjamin faz da modernidade se adéqua perfeitamente o mundo contemporâneo, onde ainda hoje, há exclusão social em virtude das transformações em nome do progresso, muitas vezes para a construção de grandes espaços comercias - que delimitam os locais de convivência a mercadoria em exposição cria no sujeito uma imagem ilusória da realidade -, e dessa forma o homem de nosso tempo, vai assumindo as características do flâneur como sujeito vagante de um espaço criado para a contemplação, seja ela nas lojas dos shopping centers, seja em sua casa ligado na sociedade em rede - falo das chamadas redes sociais -, da rede mundial de computador.

Assim, se, antes, o flâneur percorria, anonimamente, as ruas, e a
multidão era fonte de seu devaneio, por onde via e sentia o mundo,
hoje, esse personagem é o internauta anônimo, mas também
identificado como consumidor, que navega pela rede universal de
computadores, através deles se comunicando e "educando" sob a
lógica de produção privada de mercadorias, tornando-se ele próprio
em cobiçada mercadoria do século atual. (AQUINO, 2015)

Graduado em Filosofia - Licenciatura, pela Universidade Estadual Vale do Acaraú - UEVA, atualmente, Mestrando em Filosofia pela Universidade Estadual do Ceará - UECE. Brasileiro, residente em Sobral - CE. E-mail: rogellyo@hotmail.com 
Mesmo depois de terem se passado setenta e cincos anos desde o momento de sua morte até hoje Benjamin consegue ser surpreendentemente vivo em suas analises. Em dados momentos, parece que está fazendo uma leitura da contemporaneidade e das fantasmagorias presentes na vida do homem. Por esses motivos, a caracterização da modernidade elaborada pelo pensador permanece atual, configurando-se como chave fundamental também para entendemos os nossos dias.

\section{CONCLUSÃO}

Tanto pela originalidade de seu pensamento, como pela amplitude de sua obra, Walter Benjamin continua sendo um dos pensadores mais determinantes, e influentes da cultura ocidental contemporânea. A fantasmagoria apontada por ele como uma das principais características da modernidade é algo marcante em nossos tempo, isso só releva o nível de percepção, e de certa modo, desvela a seu leitor a antecipação que o filosofo fez ao falar sobre as configurações dos traços únicos que a modernidade possuiu.

O filosofo joga com as sutilezas presentes nos fazeres cotidianos para demonstrar que as coisas não estão em seus devidos lugares, havendo em todos os âmbitos da vida, uma supremacia delas sobre os sujeitos. Isso, leva o homem a criar uma imagem irreal do mundo, tanto para as relações com outros homens, como consigo mesmo. Em outros termos, Benjamin revela o que esta por trás, o que está escondido nas ações humanas na modernidade. Uma verdadeira fantasmagoria. Manifestada de forma muito clara para ele no mercado, no escritório, na divisão da vida pública e privada, nas exposições universais, na utilização do ferro, na disputa entre o engenheiro e o arquiteto, na figura do flâneur e do colecionador, na inversão do valor de uso das coisas, pelo valor de troca. Por fim, na cultura ocidental como um todo.

Nossa tentativa de expor como Benjamin compreende a modernidade a partir do conceito de fantasmagoria, e como ela cria no subconsciente do homem essa imagem ilusória, nasceu também da 
necessidade de uma leitura da contemporaneidade a partir dessa marca da modernidade, por compreendermos a singularidade do pensamento do filosofo e sua importância para as discussões da filosofia em nossos dias.

Ele como o filosofo da "descontração", em uma espécie de insite sobre o contexto em que vivia, consegue com sua pesquisa - diga-se de passagem, de modo bastante espantoso -, captar nas sutilezas do cotidiano da metrópole em construção, a fantasmagoria da cultura no mundo moderno, denunciando o entorpecimento em que vivia o homem, iludido com sua própria criação. É a partir daí que o homem cria uma imagem inexistente da realidade, que na prática, anula sua própria singularidade de sujeito de experiência e história de vida. Essas bases nos deram o pressuposto para uma análise sobre a fantasmagoria no contexto atual do capitalismo e das relações históricos sociais que são implicadas na contemporaneidade com essa imagem criada.

\section{REFERÊNCIAS}

AQUINO, L. C. A. A fantasmagoria na "Paris, capital do século XIX": Uma contribuição de Walter Benjamin à modernidade. Herramienta debate. Disponível em: <http://www.herramienta.com.ar/coloquios-yseminarios/fantasmagoria-na-paris-capital-do-seculo-xix-uma-contribuicao-dewalter-benja> Acesso em: 27 out 2015.

D'ANGELO, M., "A modernidade pelo olhar de Walter Benjamin", em Revista Estudos Avançados, número 20(56), 2006, p. 237-251.

BENJAMIN, Walter. Passagens. Belo Horizonte: Editora da UFMG, 2009.

Magia e técnica, arte e política: ensaios sobre literatura e história da cultura. São Paulo: Brasileira, 2012.

FLORES. R. L. B. Descobertas sobre o colecionador benjaminiano por entre as coleções de meu pai. Experiências de vida e reflexões: do individual ao coletivo em busca de resistência. Recordando a Walter Benjamin, justicia, historia y verdad. Escrituras de la Memoria. Disponível em < http://conti.derhuman.jus.gov.ar/2010/10/mesa-06/flores_mesa_6.pdf > Acesso em 25 out 2015. 
GEORGES-EUGÈNE HAUSSMANN abeto. In: Wikipédia: a enciclopédia livre. Disponível em: <https://pt.wikipedia.org/wiki/GeorgesEug\%C3\%A8ne_Haussmann> Acesso em: 20 out 2015.

KANG, Jaeho, $O$ espetáculo da modernidade. A crítica da cultura de Walter Benjamin, em revista Novos estudos. - CEBRAP no. 84, São Paulo 2009.

LOUIS-AUGUSTE BLANQUI abeto. In: Wikipédia: a enciclopédia livre. Disponível em: < https://pt.wikipedia.org/wiki/Louis_Auguste_Blanqui> Acesso em: 21 out 2015.

MASSAGLI, S.R. Homem da multidão e o flâneur no conto "o Homem da multidão" de edgar allan Poe. Terra roxa e outras terras. Revista de Estudos Literários. Vol 12. Jun 2013.

O QUE É A FIANERIE? abeto. In: Flanerie e linguagem. Disponível em: < http://flanerie-linguagem.blogspot.com.br/2012/02/blog-post.html> Acesso em: 23 out 2015.

SILVA, P. T. F. Observador dos panoramas e o flâneur: reflexão sobre a obra paris, a capital do século xix de walter Benjamin. Cadernos Walter Benjamin. On-line. Disponível em: < http://www.gewebe.com.br/pdf/cad13/caderno_06.pdf >. Acesso em 26 de out. 2015. 